\title{
Interaction of C1q With Pentraxin 3 and IgM Revisited: Mutational Studies With Recombinant C1q Variants
}

\author{
Isabelle Bally ${ }^{1}$, Antonio Inforzato ${ }^{2,3}$, Fabien Dalonneau ${ }^{1}$, Matteo Stravalaci ${ }^{2,3}$, \\ Barbara Bottazzi ${ }^{2}$, Christine Gaboriaud ${ }^{1}$ and Nicole M. Thielens ${ }^{1 *}$ \\ ${ }^{1}$ Université Grenoble Alpes, CEA, CNRS, IBS, Grenoble, France, ${ }^{2}$ Humanitas Clinical and Research Center, Rozzano, Italy, \\ ${ }^{3}$ Department of Biomedical Sciences, Humanitas University, Pieve Emanuele, Italy
}

OPEN ACCESS

Edited by:

Zvi Fishelson,

Tel Aviv University, Israel

Reviewed by:

Péter Gál,

Institute of Enzymology (MTA),

Hungary

Uday Kishore,

Brunel University London,

United Kingdom

*Correspondence:

Nicole M. Thielens

nicole.thielens@ibs.fr

Specialty section: This article was submitted to Molecular Innate Immunity, a section of the journal

Frontiers in Immunology

Received: 10 December 2018 Accepted: 20 February 2019

Published: 14 March 2019

Citation:

Bally I, Inforzato A, Dalonneau F, Stravalaci M, Bottazzi B, Gaboriaud C and Thielens NM (2019) Interaction of

C1q With Pentraxin 3 and IgM

Revisited: Mutational Studies With

Recombinant C1q Variants.

Front. Immunol. 10:461.

doi: 10.3389/fimmu.2019.00461
Pentraxins and complement defense collagens are soluble recognition proteins that sense pathogens and altered-self elements, and trigger immune responses including complement activation. PTX3 has been shown to interact with the globular recognition domains $(\mathrm{gC} 1 \mathrm{q})$ of the $\mathrm{C} 1 \mathrm{q}$ protein of the classical complement pathway, thereby modulating complement activity. The C1q-PTX3 interaction has been characterized previously by site-specific mutagenesis using individual gC1q domains of each of the three C1q chains. The present study is aimed at revisiting this knowledge taking advantage of full-length recombinant $\mathrm{C} 1 \mathrm{q}$. Four mutations targeting exposed amino acid residues in the $\mathrm{gC} 1 \mathrm{q}$ domain of each of the C1q chains (Lys ${ }^{\mathrm{A} 200} \mathrm{Asp}-\mathrm{Lys}^{\mathrm{A}}{ }^{201} \mathrm{Asp}$, $\mathrm{Arg}^{\mathrm{B} 108} \mathrm{Asp}-\mathrm{Arg}^{\mathrm{B} 109} \mathrm{Glu}$, Tyr ${ }^{\mathrm{B} 175} \mathrm{Leu}$, and Lys ${ }^{\mathrm{C} 170} \mathrm{Glu}$ ) were introduced in recombinant $\mathrm{C} 1 \mathrm{q}$ and the interaction properties of the mutants were analyzed using surface plasmon resonance. All $\mathrm{C} 1 \mathrm{q}$ mutants retained binding to $\mathrm{C} 1 \mathrm{r}$ and $\mathrm{C} 1 \mathrm{~s}$ proteases and mannose-binding lectin-associated serine proteases, indicating that the mutations did not affect the function of the collagen-like regions of C1q. The effect of these mutations on the interaction of C1q with PTX3 and IgM, and both the PTX3- and IgM-mediated activation of the classical complement pathway were investigated. The Lys ${ }^{\mathrm{A} 200} \mathrm{Asp}-\mathrm{Lys}^{\mathrm{A} 201} \mathrm{Asp}$ and Lys ${ }^{\mathrm{C} 170} \mathrm{Glu}$ mutants retained partial interaction with PTX3 and IgM, however they triggered efficient complement activation. In contrast, the $\mathrm{Arg}^{\mathrm{B} 108} \mathrm{Asp}-\mathrm{Arg}^{\mathrm{B} 109} \mathrm{Glu}$ mutation abolished $\mathrm{C} 1 \mathrm{q}$ binding to PTX3 and IgM, and significantly decreased complement activation. The $\mathrm{Tyr}^{\mathrm{B} 175}$ Leu mutant exhibited decreased PTX3- and IgM-dependent complement activation. Therefore, we provided evidence that, in the context of the full length C1q protein, a key contribution to the interaction with both PTX3 and IgM is given by the B chain Arg residues that line the side of the gC1q heterotrimer, with a minor participation of a Lys residue located at the apex of gC1q. Furthermore, we generated recombinant forms of the human PTX3 protein bearing either $\mathrm{D}$ or $\mathrm{A}$ at position 48 , a polymorphic site of clinical relevance in a number of infections, and observed that both allelic variants equally recognized C1q.

Keywords: complement C1q, PTX3, IgM, site-directed mutagenesis, molecular interactions, complement activation 


\section{INTRODUCTION}

Immune defense relies on the host capacity to identify pathogenic microorganisms and trigger an efficient anti-infectious response while protecting integrity of its own tissues. Pathogen sensing is mediated by constitutive innate immune molecules that are able to identify characteristic pathogen-associated molecular patterns at the surface of microbes, but also potentially noxious elements from self, such as dying cells. Recognition of these cell surface motifs elicits effector mechanisms aimed at containing early infection while instructing appropriate adaptive immune response, and supporting safe removal of apoptotic cell/debris by phagocytes $(1,2)$. Pentraxins and defense collagens are evolutionarily conserved multimeric pattern recognition proteins that are part of the humoral arm of innate immunity and play a vital role in the first line of anti-microbial defense and in the maintenance of tissue homeostasis (3).

The family of soluble complement defense collagens comprises $\mathrm{Clq}$, collectins including mannose-binding lectin (MBL) and the newly described collectin-10 (CL-K1) and collectin-11 (CL-L1), and the lectin-like proteins ficolins. C1q is the most complex defense collagen since it is composed of 3 homologous yet distinct polypeptide chains $\mathrm{A}, \mathrm{B}$, and $\mathrm{C}$ that are encoded by three different genes. Each $\mathrm{Clq}$ chain comprises an $\mathrm{N}$-terminal collagen-like sequence and a C-terminal globular gClq module and 18 chains assemble into six heterotrimeric (A-B-C) subunits (4). This hexameric structure exhibits the characteristic shape of a bouquet of flowers, with six collagenlike triple helices (stems), each terminating in a C-terminal globular trimeric head (Figure 1A). Serum C1q circulates in association with a tetramer comprising two copies of each of the homologous $\mathrm{C} 1 \mathrm{r}$ and $\mathrm{C} 1 \mathrm{~s}$ serine proteases. The resulting complex $(\mathrm{C} 1)$ has the capacity to recognize targets through the globular regions of $\mathrm{Clq}$, which triggers activation of the proteases associated to $\mathrm{Clq}$ collagen-like regions and subsequent cleavage of the complement components C4 and C2 (5). The activation fragments $\mathrm{C} 4 \mathrm{~b}$ and $\mathrm{C} 2 \mathrm{a}$ assemble at the target surface to form the C3 convertase of the classical complement pathway that cleaves $\mathrm{C} 3$, the central component of the complement system. The classical C3 convertase can also be assembled through activation of the lectin pathway that is initiated by complexes of complement collectins or ficolins and MBL-associated serine proteases (MASPs), which are homologous to $\mathrm{C} 1 \mathrm{r}$ and $\mathrm{C} 1 \mathrm{~s}$ and able to cleave $\mathrm{C} 4$ and $\mathrm{C} 2$. A third complement activation pathway involves assembly of an alternative C3 convertase containing the C3b fragment and serving to amplify C3 cleavage [reviewed in (6)].

Pentraxins are multimeric proteins with protomer subunits characterized by a conserved C-terminal domain (containing the canonical pentraxin signature $\mathrm{HxCxS} / \mathrm{TWxS}$ ) and assembled into distinctive quaternary structures. The short pentraxins $\mathrm{C}$-reactive protein (CRP) and serum amyloid $\mathrm{P}$ component (SAP) are pentameric (7), whereas pentraxin 3 (PTX3), the

\footnotetext{
Abbreviations: gC1q, globular domain of C1q; MAA, Maackia amurensis agglutinin; MASP, MBL-associated serine protease; MBL, mannose-binding lectin; SPR, surface plasmon resonance.
}

prototypic long pentraxin, contains an additional $\mathrm{N}$ terminal domain and is an octamer composed of two disulfide linked tetramers (8). Pentraxins are acute-phase proteins produced in response to inflammatory stimuli that provide protection against a wide variety of pathogens and participate in the clearance of apoptotic cells (9). PTX3 has regulatory roles in inflammation, where it has been shown to inhibit leukocyte extravasation, and plays additional functions in cancer and tissue repair (10). The three pentraxins have been shown to establish a complex crosstalk with diverse components of complement, thus affecting both the recognition and effector activities of this system. In particular, PTX3 modulates the three complement pathways through interactions with defense collagens (C1q, MBL, ficolin1 , and ficolin-2) and negative regulators of the alternative and classical/lectin $\mathrm{C} 3$ convertases, including factor $\mathrm{H}$ and $\mathrm{C} 4 \mathrm{bp}$ [reviewed in (11)].

Several studies have analyzed single nucleotide polymorphisms (SNPs) in the PTX3 gene. Amongst the 22 SNPs spanning the PTX3 gene $(\sim 25 \mathrm{~kb})$ on chromosome 3 , three are associated with susceptibility to a number of infections including those mediated by Aspergillus fumigatus (12-15), Mycobacterium tuberculosis (16) and Pseudomonas aeruginosa (17). Two of them are located in intronic regions of the gene (rs2305619 in intron 1 , and rs1840680 in intron 2, respectively), and one (missense rs3816527 in exon 2) causes a single amino-acid substitution (p.D48A) at position 48 of the preprotein sequence (i.e., in the $\mathrm{N}$-terminal domain). Epidemiological studies indicate that these three SNPs and the corresponding haplotypes are associated with different plasma levels of the protein, with the D48 exonic allele being enriched in individuals with lower systemic concentrations of PTX3 (18). This information notwithstanding, it is currently unknown whether this exonic polymorphism has qualitative (i.e., functional) in addition to quantitative effects on the crosstalk between PTX3 and the complement system, with major regard to the interaction of this long pentraxin with C1q.

In this regard, binding of C1q to immobilized PTX3 has been reported to trigger complement activation whereas fluid-phase PTX3 interferes with C1q binding to complement activators such as antigen-antibody complexes, in accordance with location of the PTX3 binding site of C1q in the $\mathrm{gClq}$ regions (19). Previous mutagenesis studies on recombinant forms of the $\mathrm{gC} 1 \mathrm{qA}, \mathrm{gClqB}$. and $\mathrm{gClqC}$ domains fused to maltose-binding protein provided initial information on the $\mathrm{Clq}$ amino acid residues at the interface of complexes formed with selected ligands, including immunoglobulins (IgG, IgM) and pentraxins (CRP, PTX3) (2023). These data highlighted the key contribution of electrostatic forces to the interaction of $\mathrm{Clq}$ with most of its ligands, and the central role of two residues, $\mathrm{Tyr}^{175}$ in $\mathrm{gClqB}$ and $\mathrm{Lys}^{170}$ in $\mathrm{gClqC}$, to recognition of PTX3 (20). We have recently produced the whole human $\mathrm{Clq}$ molecule in a recombinant form and demonstrated its structural similarity to serum-derived C1q, as judged from biochemical analysis and electron microscopy imaging. Recombinant $\mathrm{Clq}$ functionality was assessed by its capacity to associate with the $\mathrm{C} 1 \mathrm{~s}-\mathrm{C} 1 \mathrm{r}-\mathrm{C} 1 \mathrm{r}-\mathrm{C} 1 \mathrm{~s}$ tetramer, to recognize physiological C1q ligands including IgG and PTX3, and to trigger complement activation (24). Using site-directed mutagenesis, we have also identified two homologous lysine 
A

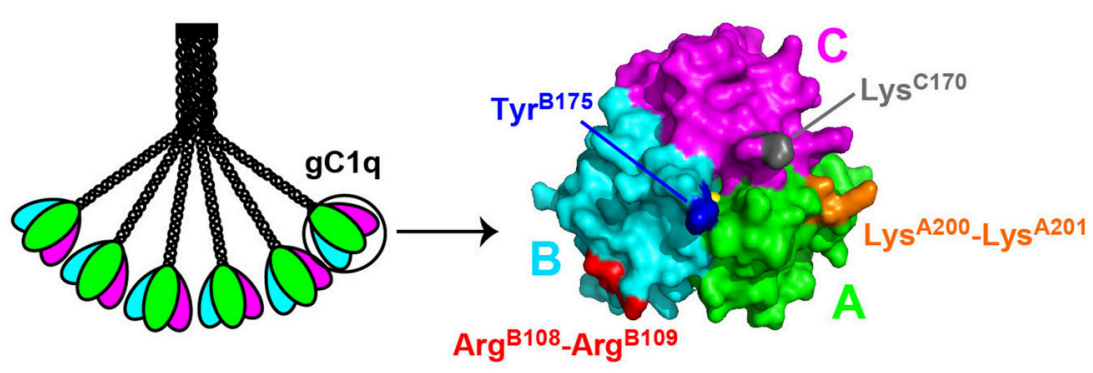

B

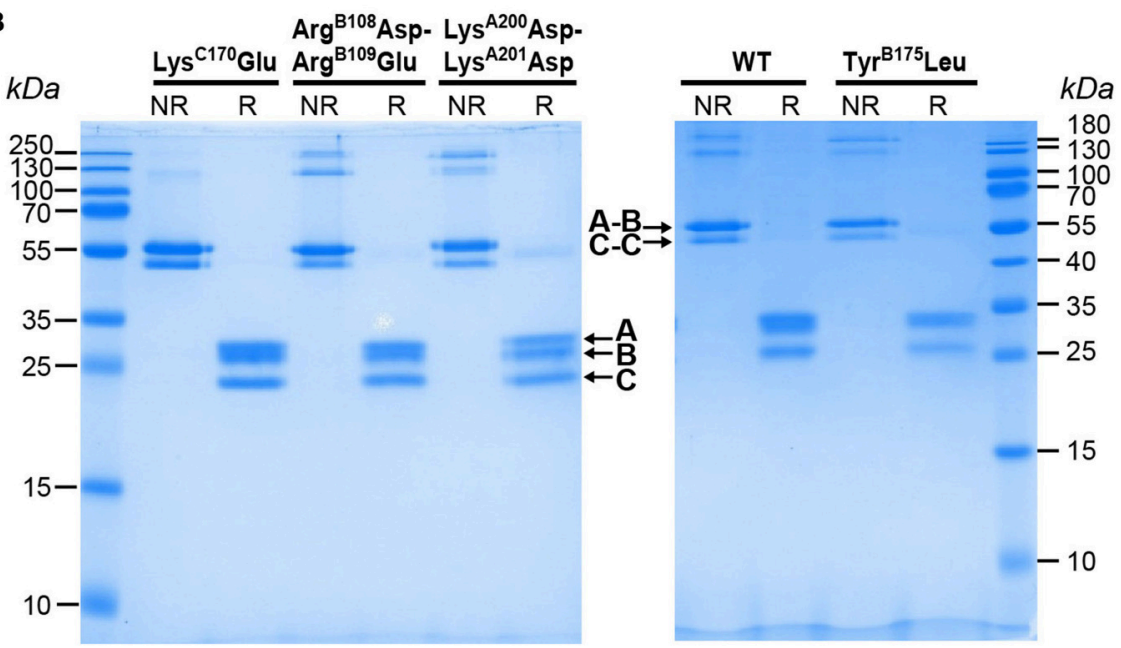

FIGURE 1 | Location of the mutated residues on gC1q structure and SDS-PAGE analysis of the C1q variants. (A) Schematic representation of the C1q molecule and 3-D structure of C1q globular domain (gC1q) with C1qA (pink), C1qB (cyan), and C1qC (green). The location of the mutated residues is indicated on the gC1q heterotrimer structure [figure generated using the Mac Pymol software; PDB ID 2wnv (35)]. Tyr ${ }^{\mathrm{B} 175}$ and Lys ${ }^{\mathrm{C} 170}$ are located at the apex of the gC1q heterotrimer and Lys $^{\mathrm{A} 200}$-Lys $^{\mathrm{A} 201}$ and $\mathrm{Arg}^{\mathrm{B} 108}$-Arg ${ }^{\mathrm{B} 109}$ are located on the side surfaces of the gC1qA and gC1qB modules, respectively. (B) SDS-PAGE analysis and Coomassie blue staining of the C1q variants, under non-reducing (NR) and reducing (R) conditions.

residues in the collagen-like sequences of the $\mathrm{B}\left(\mathrm{Lys}^{61}\right)$ and $\mathrm{C}$ $\left(\mathrm{Lys}^{58}\right)$ chains of $\mathrm{Clq}$ that play a key role in the interaction with $\mathrm{C} 1 \mathrm{r}$ and $\mathrm{C} 1 \mathrm{~s}$ and confirmed that $\mathrm{C} 1 \mathrm{q}$ shares with $\mathrm{MBL}$ and ficolins a common mechanism of interaction with its associated proteases (24).

The availability of recombinant full-length $\mathrm{C} 1 \mathrm{q}$ prompted us to revisit the C1q-PTX3 interaction using site-directed mutagenesis. To this end, we generated four $\mathrm{Clq}$ mutants targeting exposed amino acid residues in the gC1q domain of the different chains, including $\mathrm{Tyr}^{\mathrm{B} 175}$ and Lys ${ }^{\mathrm{C} 170}$ and investigated the impact of these mutations on the C1q-PTX3 interaction and the PTX3-mediated activation of the classical complement pathway. The effect on the interaction of C1q with its canonical ligand IgM was studied in parallel for comparison purposes. Furthermore, we addressed the functional impact of the p.D48A polymorphism on C1q recognition by PTX3.

\section{MATERIALS AND METHODS}

\section{Proteins and Reagents}

A recombinant form of the human PTX3 protein (with D at position 48) was made in a $\mathrm{CHO}$ cell line (25), and used in surface plasmon resonance (SPR) and complement activation experiments (see below). To assess the effect of the rs3816527 (p.D48A) polymorphism on the interaction with $\mathrm{C1q}$ in solid phase binding assays (see below), two PTX3 constructs were generated by overlapping PCR site-directed mutagenesis that contained triplets coding either for D or A at position 48 . The corresponding recombinant proteins were expressed in and purified from a HEK293 cell line as previously reported (13). Molar concentration of the recombinant PTX3 from both cell lines was estimated using a Mr value of 340,000 (26). Human IgM, bovine serum albumin (BSA) and FLAG peptide were purchased from Sigma-Aldrich. Oligonucleotides were from Eurogentec and restriction and modification enzymes from New England Biolabs. Recombinant human MASP-2 was produced in S2 cells and quantified as described previously (27).

\section{Production of the Recombinant C1s-C1r-C1r-C1s Tetramer}

The recombinant $\mathrm{C} 1 \mathrm{~s}-\mathrm{C} 1 \mathrm{r}-\mathrm{C} 1 \mathrm{r}-\mathrm{C} 1 \mathrm{~s}$ tetramer was produced in the FreeStyle 293 Expression System (Thermo Fisher), using a pcDNA3.1/Neo $(+)$ plasmid encoding human C1r with a 
Ser637Ala mutation and a C-terminal Strep-tag (kindly provided by A. Amberger and R. Gröbner, Innsbruck Medical University, Austria) and a plasmid encoding human C1s with a Cterminal FLAG epitope. The latter was generated by fusing the FLAG tag (Asp-Tyr-Lys-Asp-Asp-Asp-Asp-Lys) DNA sequence to C1s DNA (amplified using the VentR polymerase and the pFastBac-C1s plasmid (28) as a template) and cloning into a pcDNA3.1/Zeo(+) plasmid. 293-F cells grown in FreeStyle 293 medium were co-transfected with both plasmids using $293 \mathrm{fectin}$ and stable transfectants were selected with $400 \mu \mathrm{g} / \mathrm{ml}$ neomycin and $10 \mu \mathrm{g} / \mathrm{ml}$ zeocin (Thermo Fisher). Recombinant C1s-C1r-C1r-C1s was purified from the culture supernatant by chromatography on an anti-FLAG M2 affinity column (SigmaAldrich) as described by Bally et al. (24). The tetrameric assembly of the two proteins was assessed by size exclusion chromatography on a Superose 6 Increase 10/300 GL column (GE Healthcare). The molar concentration of the tetramer was estimated using a Mr value of 344,500, as determined by mass spectrometry analyses, and an absorption coefficient $(\mathrm{A} 1 \%, 1 \mathrm{~cm})$ at $280 \mathrm{~nm}$ of 13.45 (29).

\section{Production of C1q Variants}

The $\quad$ Lys $^{\mathrm{A} 200}$ Asp-Lys ${ }^{\mathrm{A} 201}$ Asp, $\quad \mathrm{Arg}^{\mathrm{B} 108}$ Asp-Arg ${ }^{\mathrm{B} 109} \mathrm{Glu}$, $\mathrm{Tyr}^{\mathrm{B} 175} \mathrm{Leu}$, and Lys ${ }^{\mathrm{C} 170}$ Glu mutations were introduced into the C1qA-, C1qB-, and C1qC-FLAG-containing pcDNA3.1/Neo(+), /Hygro(+), and /Zeo(+) plasmids, respectively, using the QuickChange XL site-directed mutagenesis kit (Agilent Technologies) (24). All constructs were checked by dsDNA sequencing (Eurofins Genomics).

Stable 293-F cell lines producing the individual B and C, A and C, or A and B chains of C1q (24), grown in FreeStyle 293 medium containing the appropriate selection antibiotics and $100 \mu \mathrm{g} / \mathrm{ml}$ ascorbic acid (Sigma-Aldrich), were transfected with the plasmids containing the C1qA Lys $^{200}$ Asp-Lys ${ }^{201}$ Asp
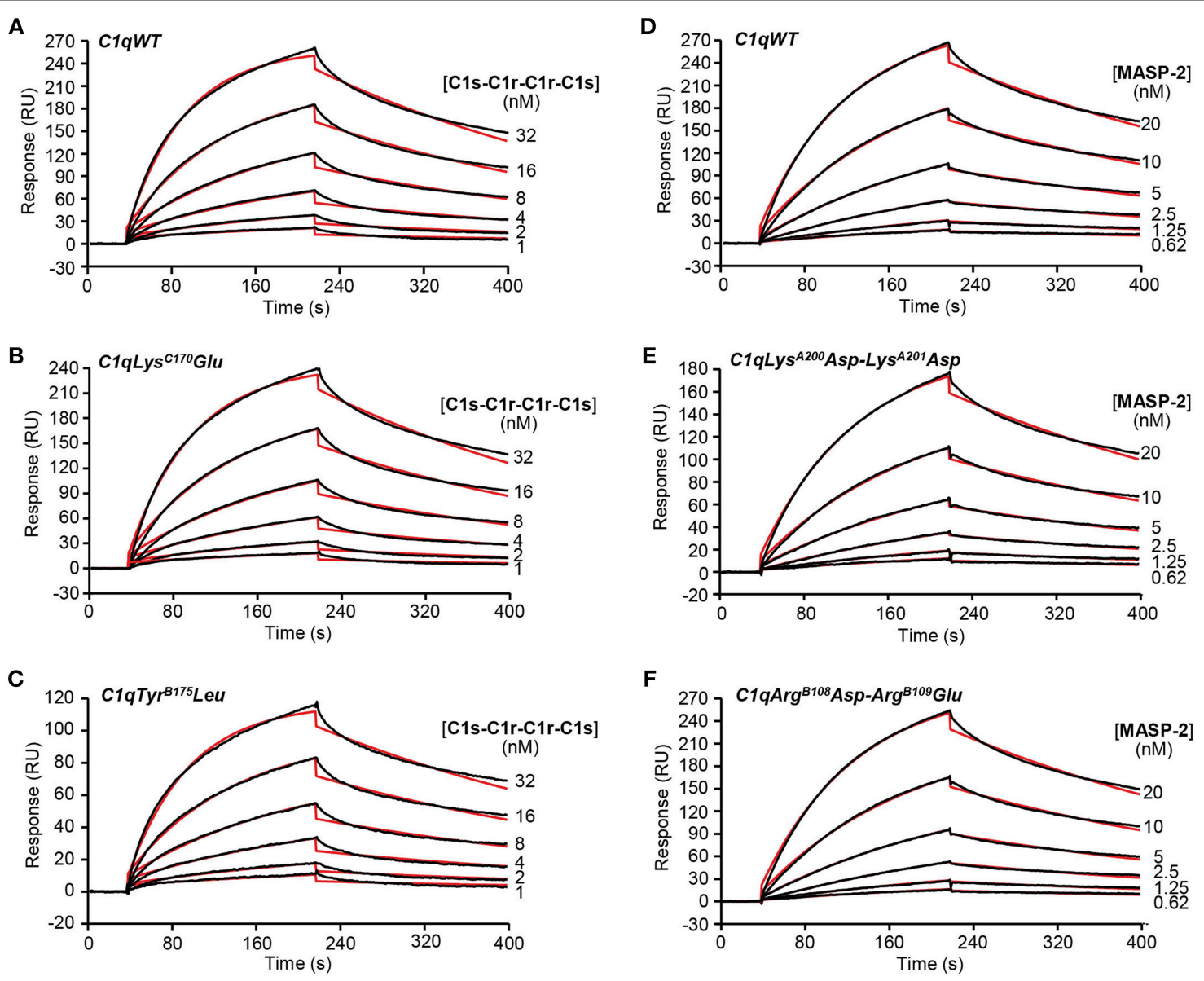

FIGURE 2 | Kinetic analyses of the interaction of the C1s-C1r-C1r-C1s tetramer and the MASP-2 dimer with immobilized C1q variants. Sixty microliter of the C1s-C1r-C1r-C1s tetramer at the indicated concentrations were injected over (A) C1qWT (16,300 RU), (B) C1qLys ${ }^{C 170}$ Glu (17,000 RU) and (C) C1qTyr ${ }^{B 175}$ Leu (12,200 RU) in $50 \mathrm{mM}$ Tris-HCl, $150 \mathrm{mM} \mathrm{NaCl}, 2 \mathrm{mM} \mathrm{CaCl}_{2}, 0.005 \%$ surfactant P20, pH 7.4 at a flow rate of $20 \mu \mathrm{l} / \mathrm{min}$. The MASP-2 dimer was injected over (D) C1qWT (13,600 RU), (E) C1qLys ${ }^{A 200}$ Asp-Lys ${ }^{A 201}$ Asp (13,000 RU), and (F) C1qArg ${ }^{B 108}$ Asp-Arg ${ }^{B 109}$ Glu (13,700 RU) under the same conditions as in (A-C). The binding signals shown were obtained by subtracting the signal over the BSA reference surface and further subtraction of buffer blanks. Fits are shown as red lines and were obtained by global fitting of the data using a 1:1 Langmuir binding model. Chi2 values were between 0.9 and 5.9. Each kinetic analysis shown is representative of two independent experiments performed on separate sensor chips. 
mutation, the $\mathrm{C} 1 \mathrm{qB}$ Arg ${ }^{108} \mathrm{Asp}-\mathrm{Arg}^{109} \mathrm{Glu}$ or $\operatorname{Tyr}^{175} \mathrm{Leu}$ mutation, or the $\mathrm{C} 1 \mathrm{qC}$ Lys ${ }^{170} \mathrm{Glu}$ mutation, respectively, using 293fectin. Stable transfectants producing the three chains were generated following additional selection with $400 \mu \mathrm{g} / \mathrm{ml}$ neomycin (Fisher Scientific), $100 \mu \mathrm{g} / \mathrm{ml}$ hygromycin (Fisher Scientific), or $10 \mu \mathrm{g} / \mathrm{ml}$ zeocin (Sigma-Aldrich), respectively.

Recombinant wild-type (WT) and mutated C1q variants were purified from the stably transfected cell culture supernatants by adsorption on insoluble IgG-ovalbumin aggregates (30) and chromatography on an anti-FLAG M2 affinity column as described previously (24). The molar concentration of the $\mathrm{Clq}$ variants was estimated using a $\mathrm{Mr}$ of 460,000 and $A_{1 \%, 1 \mathrm{~cm}}$ of 6.8 .

\section{SPR Analyses}

Analyses were performed at $25^{\circ} \mathrm{C}$ using a Biacore 3000 instrument (GE Healthcare). BSA and the C1q variants were diluted in $10 \mathrm{mM}$ sodium acetate at the following concentration and $\mathrm{pH}$ : BSA, $25 \mu \mathrm{g} / \mathrm{ml}, \mathrm{pH} 4.0$; C1q variants, $50 \mu \mathrm{g} / \mathrm{ml}, \mathrm{pH}$ 4.5 (wild-type) or 4.0 (C1q mutants), and immobilized on CM5 sensor chips (GE Healthcare) using the amine coupling chemistry in $10 \mathrm{mM}$ Hepes, $150 \mathrm{mM} \mathrm{NaCl}, 3 \mathrm{mM}$ EDTA, 0.005\% surfactant $\mathrm{P} 20, \mathrm{pH}$ 7.4. Binding of C1q partners was measured at a flow rate of $20 \mu \mathrm{l} / \mathrm{min}$ in $50 \mathrm{mM}$ Tris- $\mathrm{HCl}, 150 \mathrm{mM} \mathrm{NaCl}, 2 \mathrm{mM} \mathrm{CaCl}$, $0.005 \%$ surfactant $\mathrm{P} 20, \mathrm{pH}$ 7.4. The specific binding signal was obtained by subtracting the signal over the BSA reference surface. Regeneration of the surfaces was achieved by $10 \mu \mathrm{l}$ injections of $1 \mathrm{M} \mathrm{NaCl}, 10 \mathrm{mM}$ EDTA, and, if needed, $10-20 \mathrm{mM} \mathrm{NaOH}$. Kinetic data were analyzed by global fitting to a 1:1 Langmuir binding model for at least five concentrations simultaneously, using the BIAevaluation 3.2 software (GE Healthcare). Buffer blanks were subtracted from the data sets used for kinetic analyses. The apparent equilibrium dissociation constants $\left(K_{\mathrm{D}}\right)$ were calculated from the ratio of the dissociation and association rate constants $\left(k_{\mathrm{d}} / k_{\mathrm{a}}\right)$. Chi2 values were below 6 in all cases.

\section{Complement Activation Assays}

Microtiter plates (Maxisorp Nunc) were coated with PTX3 $(10 \mu \mathrm{g} / \mathrm{ml})$ or $\operatorname{IgM}(2 \mu \mathrm{g} / \mathrm{ml})$ in $10 \mathrm{mM} \mathrm{NaHCO}_{3}, \mathrm{pH} 9.6$ overnight at $4^{\circ} \mathrm{C}$. Wells were incubated for $1 \mathrm{~h}$ at $37^{\circ} \mathrm{C}$ with PBS containing $2 \%$ BSA (w/v) and washed with PBS containing 0.05\% Tween 20 (PBS-T). C1q-depleted serum (CompTech), diluted 1:25 in $5 \mathrm{mM}$ Na veronal, $145 \mathrm{mM} \mathrm{NaCl}, 5 \mathrm{mM} \mathrm{CaCl}$,
$1.5 \mathrm{mM} \mathrm{MgCl}_{2}, \mathrm{pH} 7.5$ and reconstituted with the recombinant C1q variants $(4 \mu \mathrm{g} / \mathrm{ml})$ was added to the wells and incubated for $1 \mathrm{~h}$ at $37^{\circ} \mathrm{C}$. The wells were washed with $5 \mathrm{mM}$ Na veronal, $145 \mathrm{mM} \mathrm{NaCl}, 5 \mathrm{mM}$ EDTA, pH 7.5 and then a rabbit antiC4 polyclonal antibody (1:1000 dilution) (Siemens Healthcare Diagnostics) was added to each well and incubated for $1 \mathrm{~h}$ at $37^{\circ} \mathrm{C}$. After washing with PBS-T and incubation with a peroxidase-conjugated goat anti-rabbit polyclonal antibody (diluted 1:20,000 in PBS-T) (Jackson ImmunoResearch) for $1 \mathrm{~h}$ at $37^{\circ} \mathrm{C}$, plates were washed with PBS-T and developed with 3,3',5,5'-tetramethylbenzidine (Tebu). The reaction was stopped with $1 \mathrm{~N} \mathrm{H}_{2} \mathrm{SO}_{4}$ and absorbance was read at $450 \mathrm{~nm}$. Each assay was performed in duplicate and absorbance values were determined after subtracting blank values obtained in the absence of added C1q. Normal human serum was obtained from the Etablissement Français du Sang Rhône-Alpes (agreement number 14-1940 regarding its use in research). Statistical analysis was performed using a paired two-tailed Student $t$-test (GraphPad software), with statistical significance defined as $P$ $\leq 0.05$.

\section{Gel Electrophoresis and Lectin Blotting}

Aliquots of purified recombinant PTX3 (either A48 and D48 from HEK293, or D48 from $\mathrm{CHO}$ ) were run under denaturing conditions on Tris acetate $3-8 \%(\mathrm{w} / \mathrm{v})$ gels (Thermo Fisher) and $8-18 \%(\mathrm{w} / \mathrm{v})$ gel cards (GE Healthcare), in the absence and presence, respectively, of dithiothreitol, as reducing agent. Following separation, protein bands were stained either with silver nitrate (ProteoSilver ${ }^{\mathrm{TM}}$ Silver Stain Kit, Sigma-Aldrich) or Cy5, according to the electrophoretic apparatus used (XCell SureLock ${ }^{\mathrm{TM}}$ Mini-Cell Electrophoresis System, Thermo Fisher, or Amersham WB System, GE Healthcare, respectively).

The oligosaccharides linked to the A48 and D48 variants of PTX3 from HEK293 were probed for linkage and content of terminal residues of sialic acid by lectin staining using the DIG Glycan Differentiation Kit (Roche). Briefly, aliquots of both preparations were resolved by SDS-PAGE on Tris-glycine $10 \%(\mathrm{w} / \mathrm{v})$ gels under reducing conditions and transferred onto Hybond-C Extra membranes. Following blocking, membranes were incubated with Maackia amurensis agglutinin (MAA, that recognizes $\alpha(2,3)$-linked sialic acid), and bound lectin revealed according to the manufacturer's instructions (26).

TABLE 1 | Kinetic and dissociation constants for binding of the $\mathrm{C}_{1} \mathrm{r}_{2}-\mathrm{C} 1 \mathrm{~s}_{2}$ tetramer and MASP-2 dimer to immobilized C1q variants.

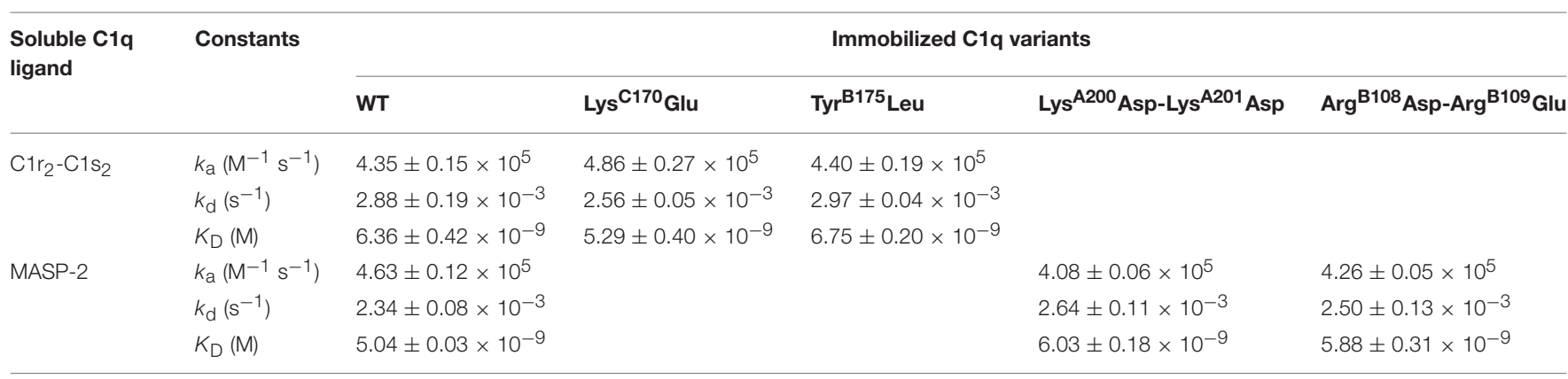

Values are the means $\pm S E$ of two to four separate experiments. 


\section{Solid Phase Binding Assays}

Binding of the A48 and D48 variants of PTX3 from HEK293 to C1q was assessed using 96 well Maxisorp plates (Nunc) coated with C1q (purified from human serum; Merck Millipore). All dilutions, incubations, and washes were performed in $50 \mathrm{mM}$ HEPES, 100 mM NaCl, 0.1\% (v/v) Tween 20, pH 7.40 (HBS-T).
Plates were coated overnight at room temperature with proteins in $20 \mathrm{mM} \mathrm{Na}_{2} \mathrm{CO}_{3}, \mathrm{pH}$ 9.6. Control wells were incubated with buffer alone and treated as for sample wells. Plates were blocked with $1 \%(\mathrm{w} / \mathrm{v}) \mathrm{BSA}$ for $2 \mathrm{~h}$ at $37^{\circ} \mathrm{C}$, and incubated with the PTX3 proteins for $1 \mathrm{~h}$ at $37^{\circ} \mathrm{C}$. Bound proteins were detected using a rabbit anti-human PTX3 polyclonal antibody $(200 \mathrm{ng} / \mathrm{ml})$

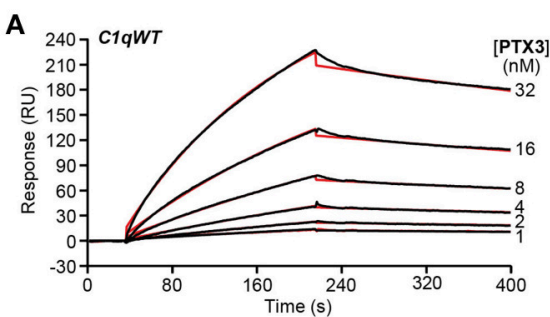

B

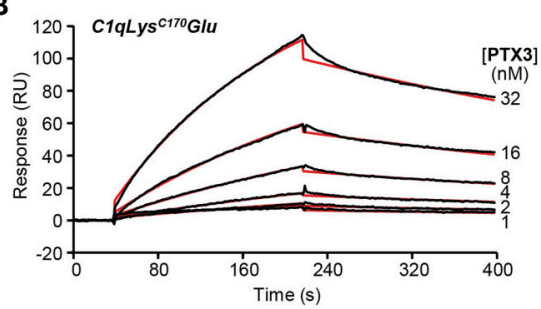

C

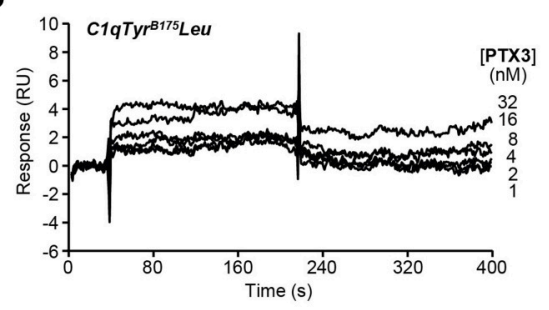

D

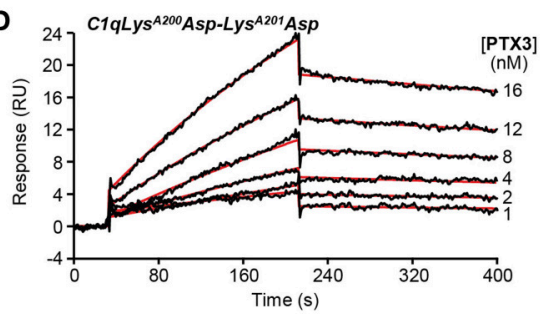

$\mathbf{E}$

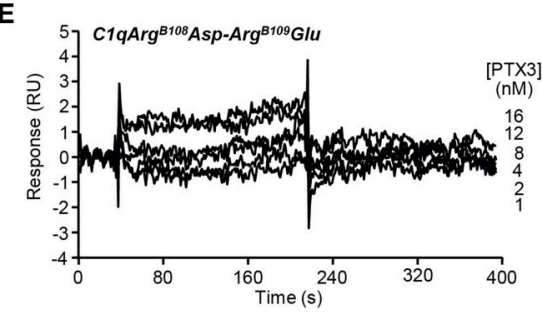

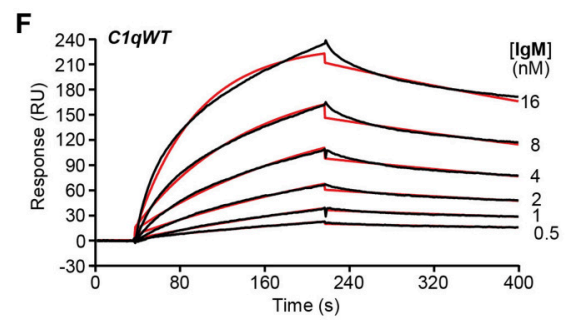

G

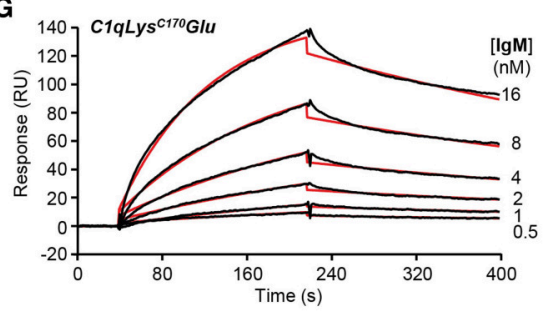

H

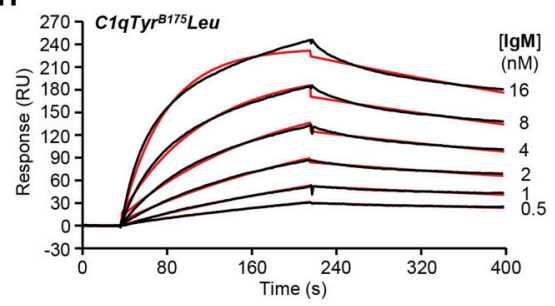

I

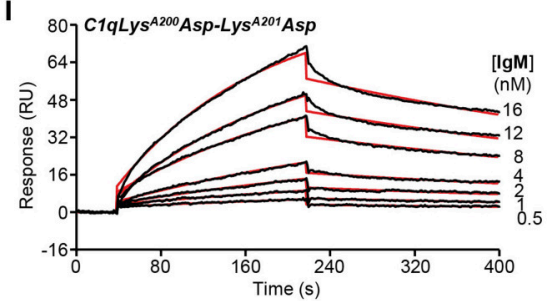

$\mathbf{J}$

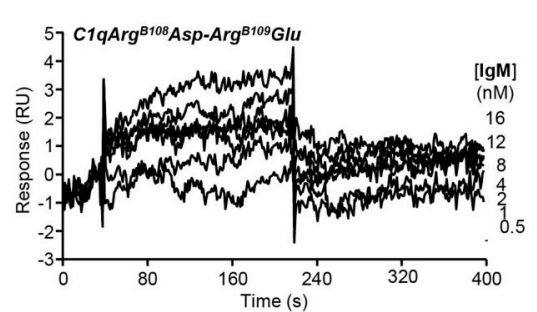

FIGURE 3 | Kinetic analyses of the interaction of PTX3 and IgM with immobilized C1q variants. Sixty microliter of PTX3 at the indicated concentrations were injected

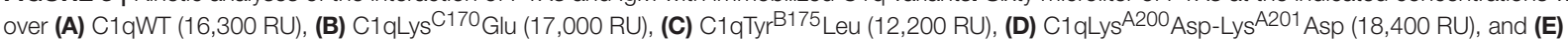

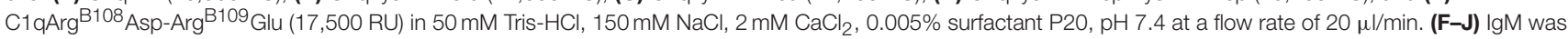
injected over the immobilized C1q variants under the same conditions as in (A-E). The binding signals shown were obtained by subtracting the signal over the BSA reference surface and further subtraction of buffer blanks. Fits are shown as red lines and were obtained by global fitting of the data using a 1:1 Langmuir binding model. Chi2 values were between 0.25 and 5.8. Each kinetic analysis shown is representative of two to five independent experiments performed on separate sensor chips. 
followed by a donkey anti-rabbit IgG HRP-conjugate whole antibody (GE Healthcare) and the 3,3,5,5'-tetramethylbenzidine substrate. Absorbance was read at $450 \mathrm{~nm}$ and background from uncoated wells subtracted.

\section{RESULTS AND DISCUSSION}

\section{Generation and Quality Control of the C1q Mutants}

Four $\mathrm{C} 1 \mathrm{q}$ mutants have been produced, with two mutations targeting residues suggested to participate in the interaction with pentraxins $\left(\mathrm{Tyr}^{\mathrm{B} 175} \mathrm{Leu}\right.$ and $\mathrm{Lys}{ }^{\mathrm{C} 170} \mathrm{Glu}$ ), and two mutations targeting exposed basic consecutive residues in the $\mathrm{A}$ and B chains (Lys ${ }^{\mathrm{A} 200}$ Asp-Lys ${ }^{\mathrm{A} 201} \mathrm{Asp}, \quad \mathrm{Arg}^{\mathrm{B} 108} \mathrm{Asp}-\mathrm{Arg}{ }^{\mathrm{B} 109} \mathrm{Glu}$ ), proposed to contribute to $\operatorname{IgG}$ and/or IgM binding $(20,21,31)$. The single mutated residues are located at the apex of the $\mathrm{gClq}$ heterotrimer whereas the tandem lysine and arginine residues are located on the side surface of gC1q (Figure 1A).

The C1q mutants were produced in stably transfected 293-F cells expressing the three $\mathrm{C} 1 \mathrm{q}$ chains and the recombinant $\mathrm{C} 1 \mathrm{q}$ variants purified from the cell culture supernatants as described for C1qWT. SDS-PAGE analysis of the four purified C1q mutants showed a band pattern similar to that obtained for C1qWT, with characteristic A-B and C-C dimers under non-reducing conditions (Figure 1B, NR lanes) and the three A, B, and C chains under reducing conditions (Figure 1B, R lanes). The minor extra bands above $100 \mathrm{kDa}$, observed only under non-reducing conditions, likely correspond to multimers of the $\mathrm{C}$ chain. This is corroborated by the lower intensity of the bands corresponding to $\mathrm{C}-\mathrm{C}$ dimers compared to A-B dimers whereas the three chains are of equal intensity under reducing conditions. It should be mentioned that these extra bands are also observed with serumderived C1q (Figure S1). Negative staining electron microscopy imaging revealed no difference between the wild-type protein and the four mutants, with individual molecules harboring a bouquet-like structure with six globular heads and a central stalk (data not shown), further indicating that the mutations had no impact on the assembly of mutated C1q.

The capacity of the $\mathrm{C} 1 \mathrm{q}$ mutants to associate with the C1s-C1r-C1r-C1s tetramer or MASP-2 dimer, the homologous protease of the lectin complement pathway, was analyzed by SPR. The proteases bound to immobilized C1qWT, in accordance with our previous data (24) and to the four C1q mutants (Figure 2). The lower binding level of the C1s-C1r-C1r-C1s tetramer observed for the $\mathrm{Tyr}^{\mathrm{B} 175}$ Leu mutant (Figure 2C) can be related to the lower immobilization level of this mutant $(12,200$ RU) by comparison with C1qWT (16,300 RU, Figure 2A) and the Lys ${ }^{\mathrm{C} 170}$ Glu mutant $(17,000 \mathrm{RU}$, Figure 2B). Kinetic analyses yielded similar binding parameters and dissociation constants for the interaction of the proteases with immobilized C1qWT and the four C1q mutants (Table 1). These data indicated that the mutations in the globular regions did not affect the capacity of the collagen-like regions of the $\mathrm{Clq}$ mutants to associate with the C1r/C1r or MASPs proteases.

\section{PTX3 and IgM Binding Properties of the C1q Variants}

SPR was further used to investigate the functional impact of the mutations on the interaction of the $\mathrm{C} 1 \mathrm{q}$ variants with PTX3 and with IgM, a major complement activating ligand of $\mathrm{C} 1 \mathrm{q}$. The amounts of immobilized $\mathrm{C} 1 \mathrm{q}$ ranged from 16,200 to $18,400 \mathrm{RU}$, except for the $\mathrm{Tyr}^{\mathrm{B} 175}$ Leu mutant, for which the immobilization level could not exceed 12,200 RU despite repeated injections. No detectable PTX3 binding was observed for the two $\mathrm{Clq}$ variants with mutated $\mathrm{B}$ chain residues (Figures 3C,E) whereas the Lys ${ }^{\mathrm{C} 170}$ Glu mutant and the Lys ${ }^{\mathrm{A} 200}$ Asp-Lys ${ }^{\mathrm{A} 201}$ Asp mutant retained the ability of C1qWT to interact with PTX3 (Figures 3B,D), although lower binding levels were observed for the latter mutant (Figures 3A,D). However, kinetic analysis of the interactions yielded $K_{\mathrm{D}}$ values of the same order, comprised between 5.65 and $10.9 \mathrm{nM}$ (Table 2), even if small differences could be detected between the mutants and C1qWT. For example, the 1.5-fold higher $k_{\mathrm{d}}$ value for the Lys ${ }^{\mathrm{C} 170} \mathrm{Glu}$ mutant may reflect a slightly lower stability of the complex and the 1.5-fold lower $k_{\mathrm{a}}$ value for the Lys ${ }^{\mathrm{A} 200} \mathrm{Asp}$ Lys ${ }^{\mathrm{A} 201}$ Asp mutant a slightly slower formation of the complex. Comparable effects were observed for binding of both $\mathrm{Clq}$ mutants to IgM, with $K_{\mathrm{D}}$ values ranging from 1.92 to $3.31 \mathrm{nM}$ (Table 2), reflecting a higher apparent affinity for IgM than for PTX3. Interestingly, the immobilized $\mathrm{Tyr}^{\mathrm{B} 175} \mathrm{Leu}$ mutant retained the ability to interact with IgM (Figure $3 \mathbf{H}$ ), with even a slightly better affinity $(0.89 \mathrm{nM})$ than C1qWT, arising mainly from a 1.5-fold higher $k_{\mathrm{a}}$ value. As observed for PTX3 binding, the $\mathrm{Arg}^{\mathrm{B} 108} \mathrm{Asp}-\mathrm{Arg}^{\mathrm{B} 109}$ Glu mutation abolished C1q capacity to

TABLE 2 | Kinetic and dissociation constants for binding of PTX3 and lgM to immobilized C1q variants.

\begin{tabular}{|c|c|c|c|c|c|c|}
\hline \multirow{2}{*}{$\begin{array}{l}\text { Soluble C1q } \\
\text { ligand }\end{array}$} & \multirow[t]{2}{*}{ Constants } & \multicolumn{5}{|c|}{ Immobilized C1q variants } \\
\hline & & WT & Lys ${ }^{\mathrm{C} 170} \mathrm{Glu}$ & $\mathrm{Tyr}^{\mathrm{B} 175}$ Leu & Lys ${ }^{A 200}$ Asp-Lys ${ }^{A 201}$ Asp & Arg $^{B 108}$ Asp-Arg ${ }^{B 109}$ Glu \\
\hline \multirow[t]{3}{*}{ PTX3 } & $k_{a}\left(\mathrm{M}^{-1} \mathrm{~s}^{-1}\right)$ & $1.55 \pm 0.21 \times 10^{5}$ & $1.40 \pm 0.01 \times 10^{5}$ & & $9.83 \pm 4.08 \times 10^{4}$ & \\
\hline & $k_{d}\left(s^{-1}\right)$ & $8.59 \pm 0.10 \times 10^{-4}$ & $1.52 \pm 0.11 \times 10^{-3}$ & ND & $6.34 \pm 0.15 \times 10^{-4}$ & ND \\
\hline & $K_{\mathrm{D}}(\mathrm{M})$ & $5.65 \pm 0.82 \times 10^{-9}$ & $1.09 \pm 0.07 \times 10^{-8}$ & & $7.84 \pm 3.37 \times 10^{-9}$ & \\
\hline \multirow[t]{3}{*}{$\lg M$} & $k_{\mathrm{a}}\left(\mathrm{M}^{-1} \mathrm{~s}^{-1}\right)$ & $9.19 \pm 2.08 \times 10^{5}$ & $6.81 \pm 0.51 \times 10^{5}$ & $1.47 \pm 0.05 \times 10^{6}$ & $7.17 \pm 2.48 \times 10^{5}$ & \\
\hline & $k_{\mathrm{d}}\left(\mathrm{s}^{-1}\right)$ & $1.54 \pm 0.19 \times 10^{-3}$ & $1.67 \pm 0.04 \times 10^{-3}$ & $1.31 \pm 0.01 \times 10^{-3}$ & $2.06 \pm 0.22 \times 10^{-3}$ & ND \\
\hline & $K_{\mathrm{D}}(\mathrm{M})$ & $1.92 \pm 0.68 \times 10^{-9}$ & $2.48 \pm 0.24 \times 10^{-9}$ & $8.92 \pm 0.41 \times 10^{-10}$ & $3.31 \pm 1.12 \times 10^{-9}$ & \\
\hline
\end{tabular}

Values are the means $\pm S E$ of two to five separate experiments. ND, not determined due to no detectable binding in the concentration range used. 
interact with IgM (Figure 3J) and the binding levels observed for the Lys ${ }^{\mathrm{A} 200} \mathrm{Asp}-\mathrm{Lys}{ }^{\mathrm{A} 201}$ Asp mutant were lower than those obtained with C1qWT (Figure 3I).

\section{PTX3- and IgM-Dependent Complement Activation by the C1q Variants}

The capacity of the $\mathrm{Clq}$ variants to trigger complement activation when added to C1q-depleted serum in microwells coated with PTX3 or IgM was analyzed by ELISA. C4b deposition in the wells results from serum $\mathrm{C} 4$ cleavage by a functional $\mathrm{C} 1$ complex assembled from recombinant $\mathrm{Clq}$ and the serum $\mathrm{C} 1 \mathrm{r} / \mathrm{C} 1$ s proteases. As expected, C1qWT yielded amounts of deposited $\mathrm{C} 4 \mathrm{~b}$ comparable to those obtained with complement-sufficient normal human serum (NHS) in both PTX3 and IgM coated plates. In accordance with the SPR data, no significant difference was observed between the Lys ${ }^{\mathrm{C} 170} \mathrm{Glu}$ mutant and $\mathrm{C} 1 \mathrm{qWT}$ whereas the $\mathrm{Arg}^{\mathrm{B} 108}$ Asp$\mathrm{Arg}^{\mathrm{B} 109} \mathrm{Glu}$ mutation strongly decreased both PTX3- and IgMdependent complement activation (30 and $9 \%$ of the signal obtained with C1qWT, respectively) (Figure 4). The $\mathrm{Tyr}^{\mathrm{B} 175} \mathrm{Leu}$ mutant also exhibited significantly decreased PTX3- and IgMmediated complement activating capacity ( 44.5 and $61.4 \%$ of the C1qWT value, respectively), in apparent discrepancy with the SPR data that detected no binding of PTX3 (Figure 3C) and a strong interaction with IgM (Figure $3 \mathrm{H}$ ). As mentioned above, an immobilization level comparable to that of the other mutants (>16,000 RU) could not be reached for the $\mathrm{Tyr}^{\mathrm{B} 175}$ Leu mutant $(12,200 \mathrm{RU})$ and the lack of PTX 3 binding might be explained by a possible threshold effect. The fact that the interaction with IgM was not affected under the same C1q immobilization conditions might result from a difference in the avidity component of the interactions between hexameric C1q and multivalent PTX3 or IgM. However, it cannot be excluded that the covalent immobilization of this mutant might have influenced its PTX3 binding capacity. In addition, the complement activating assay is performed using coated PTX3 or IgM and the SPR experiments in the reverse configuration (immobilized C1q variants), which might account for the observed discrepancy. Another interesting observation is the fact that the Lys ${ }^{\mathrm{A} 200} \mathrm{Asp}-\mathrm{Lys}{ }^{\mathrm{A} 201}$ Asp mutant exhibited significantly higher PTX3-dependent complement activating capacity (163\% of C1qWT, Figure $4 \mathrm{~A}$ ), which might be linked to the slightly higher stability of the complex observed in SPR experiments.

\section{The D48 and A48 Allelic Variants of PTX3 and Their C1q Binding Properties}

To assess if the exonic polymorphism p.D48A in the PTX3 gene affects the protein's binding to C1q, recombinant forms of the D48 and A48 allelic variants were made in a HEK293 cell line and purified by immunoaffinity chromatography as previously described (13). SDS-PAGE analysis, performed on Tris acetate 3-8\% gels under non-reducing conditions (Figure 5A), revealed a major band with an apparent molecular mass of $340 \mathrm{kDa}$, consistent with PTX3 protomers being mainly assembled into octamers stabilized by disulfide bonds, in both preparations. Additional bands were detected at apparent molecular masses of $280,210,170,80$, and $65 \mathrm{kDa}$, and this pattern was consistent amongst the two allelic variants made in HEK293 and the $\mathrm{CHO}$ protein, here used as a reference (8). Upon reduction, a major band at $42 \mathrm{kDa}$ (close to the expected molecular mass for PTX3 monomers, i.e., $\sim 42.5 \mathrm{kDa}$ ) and a minor one at $100 \mathrm{kDa}$ (likely corresponding to dimers of the protein, originating from partial reduction) were observed following $\mathrm{Cy} 5$ staining in all PTX3 proteins (Figure 5B). Therefore, no significant difference in terms of quaternary structure and homogeneity was noticed amongst the D48 and A48 allelic variants, and the electrophoretic profiles of these proteins under both reducing and non-reducing conditions were comparable to that of the CHO-derived PTX3, taken as a reference. Given that protein glycosylation has been implicated in a number of PTX3 functions in innate immunity and inflammation (32), and, most importantly, sialic acid has been shown to modulate the interaction of PTX3 with
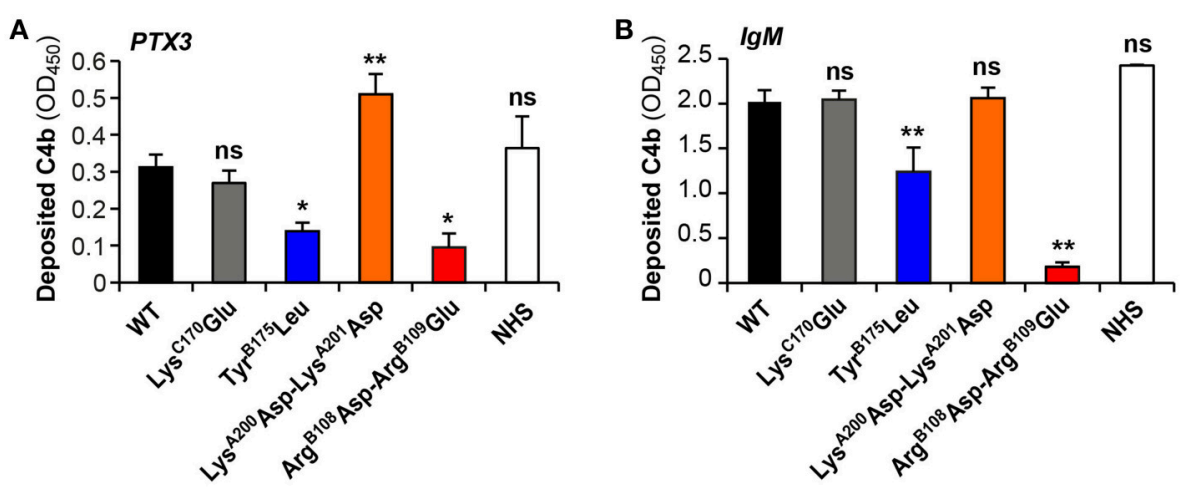

FIGURE 4 | PTX3- and IgM-dependent complement activation by the C1q variants. C1q-depleted serum (1:25 dilution) was reconstituted with the recombinant C1q variants $(4 \mu \mathrm{g} / \mathrm{ml})$ and added to microwells coated with $10 \mu \mathrm{g} / \mathrm{ml}$ PTX3 (A) or $2 \mu \mathrm{g} / \mathrm{ml}$ lgM (B). Normal human serum (NHS, $1: 25$ dilution) was used as a control. The resulting C1-cleaving activity was measured by a C4b deposition assay as described under Material and Methods. Deposited C4b was detected with an anti-human polyclonal antibody, and results are expressed as absorbance at $450 \mathrm{~nm}\left(\mathrm{OD}_{450}\right)$, following background subtraction [means \pm SEM of three (IgM) and four (PTX3) independent experiments]. Comparisons between $\mathrm{C} 1 \mathrm{qWT}$ and each of the mutants or $\mathrm{C} 1 \mathrm{q}$ in normal human serum were made using a paired Student $t$-test. ${ }^{\star} P<$ $0.05 ;{ }^{* \star} P<0.005$; ns, not significant. 

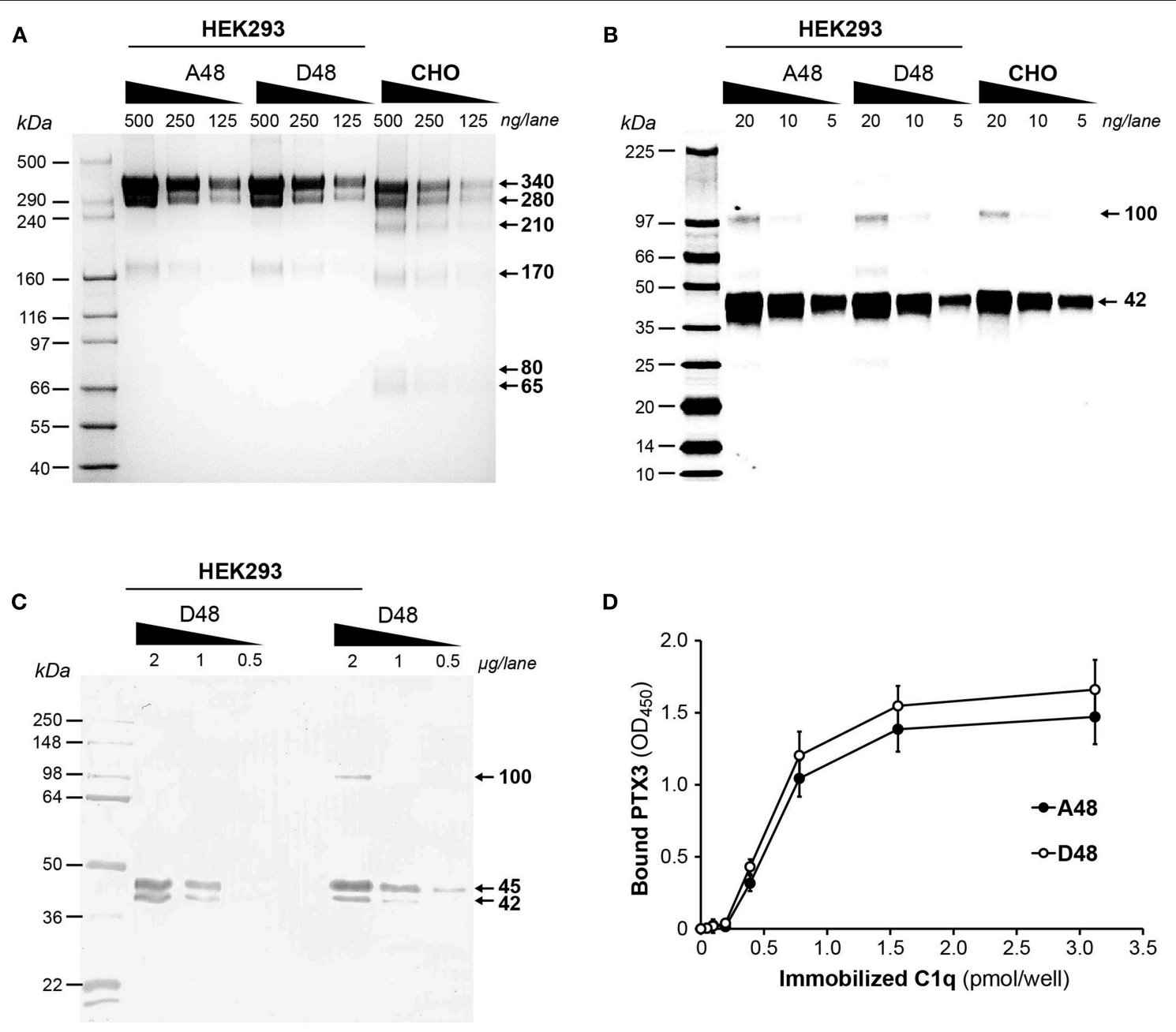

FIGURE 5 | Biochemical characterization of the D48 and A48 allelic variants of PTX3 and their binding to C1q. The indicated amounts of purified recombinant PTX3 (either A48 and D48 from HEK293, or D48 from CHO) were run under denaturing conditions on Tris acetate 3-8\% (w/V) gels (A) and 8-18\% (w/V) gel cards (B), in the absence and presence, respectively, of dithiothreitol. Following separation, protein bands were stained either with silver nitrate (A) or Cy5 (B). (C) Aliquots of both A48 and D48 preparations from HEK293 were resolved on Tris-glycine 10\% (w/v) gels under reducing conditions, transferred onto membranes, and probed with MAA lectin. (A-C) representative gels from three independent experiments are shown, with molecular mass markers on the left, and apparent molecular mass values observed for the resolved bands on the right. (D) The effect of the p.D48A polymorphism on the interaction of PTX3 with C1q was assessed by solid phase binding assay using microwells coated with the indicated amounts of C1q that were incubated with the A48 and D48 variants (both at 3 nM). Bound PTX 3 was revealed with an anti-human polyclonal antibody, and results are expressed as absorbance at $450 \mathrm{~nm}\left(\mathrm{OD}_{450}\right)$, following background subtraction (three independent experiments performed in quadruplicate, $n=12$, mean \pm SD).

C1q (33), we analyzed the sialylation status of the D48 and A48 allelic variants by lectin blotting, using MAA to probe the terminal $\alpha(2,3)$-linked sialic acid residues. As shown in Figure 5C, both proteins gave two major MAA-reactive bands at 45 and $42 \mathrm{kDa}$, indicative of glycoform populations with distinct sialylation (possibly, bi- and tri-antennary complex oligosaccharides), and a minor signal at $100 \mathrm{kDa}$ (likely corresponding to protein dimers, as described in Figure 5B). Therefore, the two recombinant variants of PTX3 were virtually identical in terms of quaternary structure and glycosylation, thus amenable to comparative functional studies. In this regard, when assayed in solid phase binding experiments, the D48 and A48 alleles had comparable binding to plastic-immobilized C1q at each applied concentration (Figure 5D), indicating that in the described experimental conditions the p.D48A polymorphism does not affect the interaction of PTX3 with C1q.

\section{CONCLUSION}

The present study aimed at revisiting the PTX3-C1q interaction using mutagenesis of full-length recombinant $\mathrm{Clq}$, as compared to the canonical $\mathrm{C} 1 \mathrm{q}$ ligand IgM. We confirmed previous observations of an essential role of the $\mathrm{B}$ chain residues Arg ${ }^{108}$, $\mathrm{Arg}^{109}$, and $\mathrm{Tyr}^{175}$ in the interaction with both PTX3 (20) and $\operatorname{IgM}(21,34)$. Our results also suggest no significant contribution of the exposed C1qA Lys ${ }^{200}$ and Lys $^{201}$ in IgM-mediated complement activation, in contrast to 


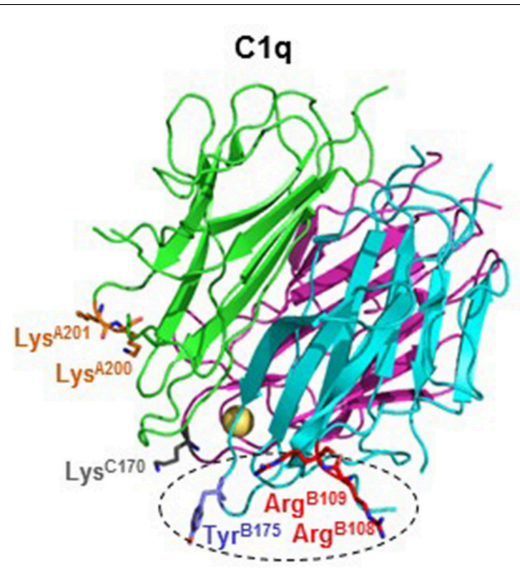

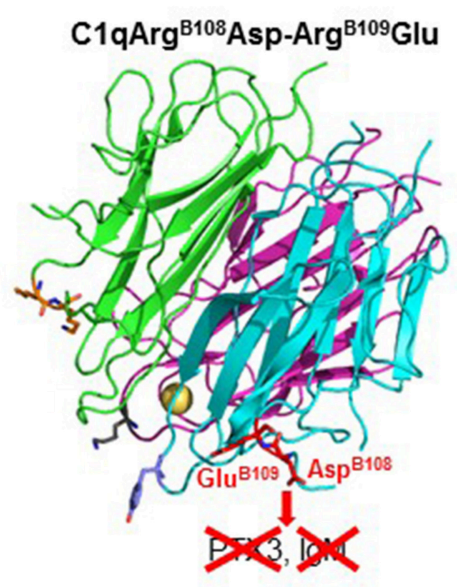

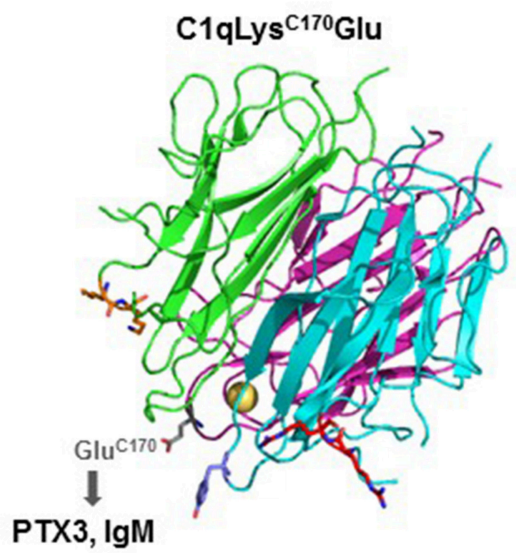

\section{C1qTyr ${ }^{B 175}$ Leu}
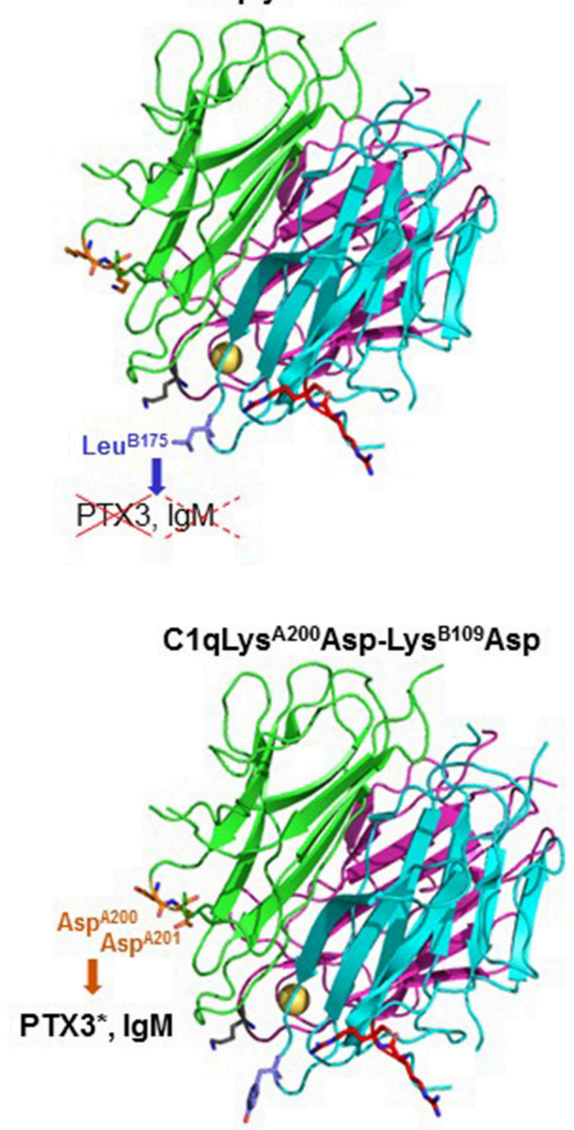

FIGURE 6 | Summary of the C1q mutagenesis results. Ribbon diagrams of the structure of the globular domains of wild-type C1q and of the four mutants are shown. The side chains of the mutated amino acid residues are represented as stick models. The color code for the three $\mathrm{C} 1 \mathrm{q}$ chains and the mutated amino acids is the same as in Figure 1. The calcium ion is represented by a yellow sphere. The gC1q region found important for interaction with both PTX3 and lgM and complement activation is delineated by dots. The effects of the C1q mutations toward PTX3 and lgM binding and complement activation are represented as follows: red crosses (solid lines), inhibition of both activities; red crosses (dotted lines), inhibition of complement activation only; bold characters, no significant inhibition. PTX3* indicates that enhancement of PTX3-dependent complement activation was observed.

previous data obtained with the isolated recombinant $\mathrm{gClqA}$ module showing that the $\mathrm{Lys}^{\mathrm{A} 200} \mathrm{Glu}$ mutation resulted in a $27 \%$ reduction in the binding to solid-phase $\operatorname{IgM}(21)$.
Intriguingly, the replacement of these two basic residues by acidic residues in the side part of gC1qA significantly enhanced the complement activating capacity of PTX3, which might be 
related to the slightly better stability of the complex observed in SPR experiments. In a similar way, the C chain Lys ${ }^{170} \mathrm{Glu}$ mutation had no significant impact on the PTX3 or IgM binding and the complement activating properties of $\mathrm{Clq}$, in contrast to previous observations showing a considerable reduction in $\mathrm{gClqC}$ binding to solid-phase PTX3 (about 40\%) (20) and IgM (>30\%) (21). These data suggest a differential exposure of $\mathrm{Lys}^{\mathrm{A} 200}$ and $\mathrm{Lys}^{\mathrm{C} 170}$ in the isolated $\mathrm{gC} 1 \mathrm{qA} / \mathrm{gC} 1 \mathrm{qC}$ modules and in the heterotrimeric globular heads of fulllength C1q. Altogether, these mutagenesis results confirm a key electrostatic contribution in the interaction between C1q B chain and PTX3 or IgM (summarized in Figure 6), consistent with the hypothesis that binding of $\mathrm{Clq}$ to targets through this region triggers efficient activation of the $\mathrm{C} 1$ complex $(35,36)$.

Given that the exonic polymorphism p.D48A (or rs3816527) in the PTX3 gene forms with rs2305619 in intron 1 and rs 1840680 in intron 2 an haplotypic block that has been linked to the susceptibility to selected infections as well as different circulating levels of the protein, it was important to assess whether this amino acid substitution had any effect on $\mathrm{Clq}$ recognition. To this end, we generated recombinant forms of the A48 and D48 alleles that were comparable in quaternary structure, homogeneity and sialylation status, thus being amenable to comparative studies. These preparations had similar binding to $\mathrm{C} 1 \mathrm{q}$, which indicates that the p.D48A polymorphism does not alter the C1q binding properties of PTX3, at least in the applied experimental conditions. In addition, we have previously shown that the C-terminal domain of PTX3 mostly mediates the interaction of the long pentraxin with $\mathrm{C} 1 \mathrm{q}$ (25), and this is modulated by protein glycosylation (at $\mathrm{Asn}^{220}$ in the Cterminal domain). Molecular dynamics simulations suggest that the PTX3 oligosaccharides (via their terminal residues of sialic acid) are in contact with polar amino acids on the solvent exposed surface of the C-terminal domain (33). Given the prominent electrostatic nature of the PTX3-C1q interaction, as supported by our study and previous evidence (20), it is tempting to speculate that these residues are involved in $\mathrm{C} 1 \mathrm{q}$ recognition. Further studies are needed to challenge this hypothesis and identify the PTX3 residues that support $\mathrm{C} 1 \mathrm{q}$ binding. Finally, the novel $\mathrm{C} 1 \mathrm{q}$ mutants generated in this study should allow further exploration

\section{REFERENCES}

1. Medzhitov R. Recognition of microorganisms and activation of the immune response. Nature. (2007) 449:819-26. doi: 10.1038/nature06246

2. Paidassi H, Tacnet-Delorme P, Arlaud GJ, Frachet P. How phagocytes track down and respond to apoptotic cells. Crit Rev Immunol. (2009) 29:111-30. doi: 10.1615/CritRevImmunol.v29.i2.20

3. Bottazzi B, Doni A, Garlanda C, Mantovani A. An integrated view of humoral innate immunity: pentraxins as a paradigm. Annu Rev Immunol. (2010) 28:157-83. doi: 10.1146/annurev-immunol-030409-101305

4. Reid KBM. Complement component C1q: historical perspective of a functionally versatile, and structurally unusual, serum protein. Front Immunol. (2018) 9:764. doi: 10.3389/fimmu.2018. 00764 of the molecular bases of $\mathrm{Clq}$ binding versatility in different physiological contexts.

\section{DATA AVAILABILITY}

The datasets generated for this study are available on request to the corresponding author.

\section{AUTHOR CONTRIBUTIONS}

NT and CG designed the study. IB, NT, MS, and AI performed the research. $\mathrm{IB}, \mathrm{CG}, \mathrm{AI}, \mathrm{BB}$, and $\mathrm{NT}$ analyzed the data. FD, $\mathrm{AI}$, and $\mathrm{BB}$ contributed key reagents. NT wrote the manuscript draft. All authors revised and approved the final version of the manuscript.

\section{FUNDING}

This work was supported by the French National Research Agency (grants ANR-16-CE11-0019 and ANR-16-CE91-000401). AI is recipient of a Young Investigator Grant from Ministero della Salute (GR-2011-02349539). The European Research Council (grant PHII-669415) is gratefully acknowledged.

\section{ACKNOWLEDGMENTS}

We thank A. Amberger and R. Gröbner (Innsbruck Medical University, Austria) for kindly providing the pcDNA3.1/Zeo(+) plasmid encoding human C1r with a Ser ${ }^{637}$ Ala mutation and a Strep-tag. This work used the platforms of the Grenoble EricInstruct center (ISBG; UMS 3518 CNRS-CEA-UJF-EMBL) with support from FRISBI (ANR-10-INSB-05-02) and GRAL (ANR10-LABX-49-01) within the Grenoble Partnership for Structural Biology (PSB). We thank Anne Chouquet and Jean-Baptiste Reiser for assistance and access to the SPR facility.

\section{SUPPLEMENTARY MATERIAL}

The Supplementary Material for this article can be found online at: https://www.frontiersin.org/articles/10.3389/fimmu. 2019.00461/full\#supplementary-material

5. Lu J, Kishore U. C1 Complex: an adaptable proteolytic module for complement and non-complement functions. Front Immunol. (2017) 8:592. doi: 10.3389/fimmu.2017.00592

6. Merle NS, Church SE, Fremeaux-Bacchi V, Roumenina LT. Complement system part I - molecular mechanisms of activation and regulation. Front Immunol. (2015) 6:262. doi: 10.3389/fimmu.2015.00262

7. Srinivasan N, White HE, Emsley J, Wood SP, Pepys MB, Blundell TL. Comparative analyses of pentraxins: implications for protomer assembly and ligand binding. Structure. (1994) 2:1017-27. doi: 10.1016/S0969-2126(94)00105-7

8. Inforzato A, Rivieccio V, Morreale AP, Bastone A, Salustri A, Scarchilli L, et al. Structural characterization of PTX3 disulfide bond network and its multimeric status in cumulus matrix organization. J Biol Chem. (2008) 283:10147-61. doi: 10.1074/jbc.M708535200 
9. Du Clos TW. Pentraxins: structure, function, and role in inflammation. ISRN Inflamm. (2013) 2013:379040. doi: 10.1155/2013/379040

10. Garlanda C, Bottazzi B, Magrini E, Inforzato A, Mantovani A. PTX3, a humoral pattern recognition molecule, in innate immunity, tissue repair, and cancer. Physiol Rev. (2018) 98:623-39. doi: 10.1152/physrev.00016. 2017

11. Inforzato A, Doni A, Barajon I, Leone R, Garlanda C, Bottazzi B, et al. PTX3 as a paradigm for the interaction of pentraxins with the complement system. Semin Immunol. (2013) 25:79-85. doi: 10.1016/j.smim.2013. 05.002

12. Brunel AS, Wojtowicz A, Lamoth F, Spertini O, Neofytos D, Calandra T, et al. Pentraxin-3 polymorphisms and invasive mold infections in acute leukemia patients receiving intensive chemotherapy. Haematologica. (2018) 103:e527-30. doi: 10.3324/haematol.2018.195453

13. Cunha C, Aversa F, Lacerda JF, Busca A, Kurzai O, Grube M, et al. Genetic PTX3 deficiency and aspergillosis in stem-cell transplantation. N Engl J Med. (2014) 370:421-32. doi: 10.1056/NEJMoa1211161

14. Fisher CE, Hohl TM, Fan W, Storer BE, Levine DM, Zhao LP, et al. Validation of single nucleotide polymorphisms in invasive aspergillosis following hematopoietic cell transplantation. Blood. (2017) 129:2693-701. doi: 10.1182/blood-2016-10-743294

15. Wojtowicz A, Lecompte TD, Bibert S, Manuel O, Rueger S, Berger C, et al. PTX3 polymorphisms and invasive mold infections after solid organ transplant. Clin Infect Dis. (2015) 61:619-22. doi: 10.1093/cid/civ386

16. Olesen R, Wejse C, Velez DR, Bisseye C, Sodemann M, Aaby P, et al. DC-SIGN (CD209), pentraxin 3 and vitamin D receptor gene variants associate with pulmonary tuberculosis risk in West Africans. Genes Immun. (2007) 8:456-67. doi: $10.1038 /$ sj.gene.6364410

17. Chiarini M, Sabelli C, Melotti P, Garlanda C, Savoldi G, Mazza C, et al. PTX3 genetic variations affect the risk of Pseudomonas aeruginosa airway colonization in cystic fibrosis patients. Genes Immun. (2010) 11:665-70. doi: 10.1038/gene.2010.41

18. Barbati E, Specchia C, Villella M, Rossi ML, Barlera S, Bottazzi B, et al. Influence of pentraxin 3 (PTX3) genetic variants on myocardial infarction risk and PTX3 plasma levels. PLoS ONE. (2012) 7:e53030. doi: 10.1371/journal.pone.0053030

19. Nauta AJ, Bottazzi B, Mantovani A, Salvatori G, Kishore U, Schwaeble WJ, et al. Biochemical and functional characterization of the interaction between pentraxin 3 and C1q. Eur J Immunol. (2003) 33:465-73. doi: 10.1002/immu.200310022

20. Roumenina LT, Ruseva MM, Zlatarova A, Ghai R, Kolev M, Olova N, et al. Interaction of $\mathrm{Clq}$ with IgG1, C-reactive protein and pentraxin 3: mutational studies using recombinant globular head modules of human $\mathrm{C} 1 \mathrm{q} \mathrm{A}, \mathrm{B}$, and C chains. Biochemistry. (2006) 45:4093-104. doi: 10.1021/bi052646f

21. Gadjeva MG, Rouseva MM, Zlatarova AS, Reid KB, Kishore U, Kojouharova MS. Interaction of human $\mathrm{C} 1 \mathrm{q}$ with $\operatorname{IgG}$ and IgM: revisited. Biochemistry. (2008) 47:13093-102. doi: 10.1021/bi801131h

22. Kishore U, Gupta SK, Perdikoulis MV, Kojouharova MS, Urban BC, Reid KB. Modular organization of the carboxyl-terminal, globular head region of human C1q A, B, and C chains. J Immunol. (2003) 171:812-20. doi: 10.4049/jimmunol.171.2.812

23. Kojouharova MS, Gadjeva MG, Tsacheva IG, Zlatarova A, Roumenina LT, Tchorbadjieva MI, et al. Mutational analyses of the recombinant globular regions of human $\mathrm{Clq} \mathrm{A}, \mathrm{B}$, and $\mathrm{C}$ chains suggest an essential role for arginine and histidine residues in the C1q-IgG interaction. J Immunol. (2004) 172:4351-8. doi: 10.4049/jimmunol.172.7.4351

24. Bally I, Ancelet S, Moriscot C, Gonnet F, Mantovani A, Daniel R, et al. Expression of recombinant human complement $\mathrm{C} 1 \mathrm{q}$ allows identification of the C1r/C1s-binding sites. Proc Natl Acad Sci USA. (2013) 110:8650-5. doi: 10.1073/pnas.1304894110

25. Bottazzi B, Vouret-Craviari V, Bastone A, De Gioia L, Matteucci C, Peri $\mathrm{G}$, et al. Multimer formation and ligand recognition by the long pentraxin
PTX3. Similarities and differences with the short pentraxins C-reactive protein and serum amyloid P component. J Biol Chem. (1997) 272:32817-23. doi: 10.1074/jbc.272.52.32817

26. Inforzato A, Baldock C, Jowitt TA, Holmes DF, Lindstedt R, Marcellini M, et al. The angiogenic inhibitor long pentraxin PTX3 forms an asymmetric octamer with two binding sites for FGF2. J Biol Chem. (2010) 285:17681-92. doi: $10.1074 /$ jbc.M109.085639

27. Lacroix M, Tessier A, Dumestre-Perard C, Vadon-Le Goff S, Gout E, Bruckner-Tuderman L, et al. Interaction of complement defence collagens C1q and mannose-binding lectin with BMP-1/tolloid-like proteinases. Sci Rep. (2017) 7:16958. doi: 10.1038/s41598-017-17318-w

28. Rossi V, Teillet F, Thielens NM, Bally I, Arlaud GJ. Functional characterization of complement proteases C1s/mannan-binding lectin-associated serine protease-2 (MASP-2) chimeras reveals the higher C4 recognition efficacy of the MASP-2 complement control protein modules. J Biol Chem. (2005) 280:41811-8. doi: 10.1074/jbc.M503813200

29. Bally I, Rossi V, Lunardi T, Thielens NM, Gaboriaud C, Arlaud GJ. Identification of the C1q-binding sites of human C1r and C1s: a refined threedimensional model of the C1 complex of complement. J Biol Chem. (2009) 284:19340-8. doi: 10.1074/jbc.M109.004473

30. Arlaud GJ, Sim RB, Duplaa AM, Colomb MG. Differential elution of Clq, $\mathrm{Clr}$ and $\mathrm{Cls}$ from human $\mathrm{Cl}$ bound to immune aggregates. Use in the rapid purification of $\mathrm{Cl}$ subcomponents. Mol Immunol. (1979) 16:445-50. doi: 10.1016/0161-5890(79)90069-5

31. Gaboriaud C, Juanhuix J, Gruez A, Lacroix M, Darnault C, Pignol D, et al. The crystal structure of the globular head of complement protein $\mathrm{C1q}$ provides a basis for its versatile recognition properties. J Biol Chem. (2003) 278:46974-82. doi: 10.1074/jbc.M307764200

32. Inforzato A, Reading PC, Barbati E, Bottazzi B, Garlanda C, Mantovani A. The "sweet" side of a long pentraxin: how glycosylation affects PTX3 functions in innate immunity and inflammation. Front Immunol. (2012) 3:407. doi: 10.3389/fimmu.2012.00407

33. Inforzato A, Peri G, Doni A, Garlanda C, Mantovani A, Bastone A, et al. Structure and function of the long pentraxin PTX3 glycosidic moiety: finetuning of the interaction with $\mathrm{C} 1 \mathrm{q}$ and complement activation. Biochemistry. (2006) 45:11540-51. doi: 10.1021/bi0607453

34. Zlatarova AS, Rouseva M, Roumenina LT, Gadjeva M, Kolev M, Dobrev I, et al. Existence of different but overlapping IgG- and IgM-binding sites on the globular domain of human C1q. Biochemistry. (2006) 45:9979-88. doi: 10.1021/bi060539v

35. Garlatti V, Chouquet A, Lunardi T, Vives R, Paidassi H, Lortat-Jacob H, et al. Cutting edge: $\mathrm{C} 1 \mathrm{q}$ binds deoxyribose and heparan sulfate through neighboring sites of its recognition domain. J Immunol. (2010) 185:808-12. doi: 10.4049/jimmunol.1000184

36. Kojouharova M, Reid K, Gadjeva M. New insights into the molecular mechanisms of classical complement activation. Mol Immunol. (2010) 47:2154-60. doi: 10.1016/j.molimm.2010.05.011

Conflict of Interest Statement: Pending patent application by NT and IB: Method for preparing $\mathrm{C} 1 \mathrm{q}$ recombinant protein (WO2014 057437).

The remaining authors declare that the research was conducted in the absence of any commercial or financial relationships that could be construed as a potential conflict of interest.

Copyright (C) 2019 Bally, Inforzato, Dalonneau, Stravalaci, Bottazzi, Gaboriaud and Thielens. This is an open-access article distributed under the terms of the Creative Commons Attribution License (CC BY). The use, distribution or reproduction in other forums is permitted, provided the original author(s) and the copyright owner(s) are credited and that the original publication in this journal is cited, in accordance with accepted academic practice. No use, distribution or reproduction is permitted which does not comply with these terms. 